\title{
Liraglutide and obesity: a review of the data so far
}

This article was published in the following Dove Press journal:

Drug Design, Development and Therapy

30 March 2015

Number of times this article has been viewed

\author{
Ellen E Ladenheim \\ Department of Psychiatry and \\ Behavioral Sciences, Johns Hopkins \\ University School of Medicine, \\ Baltimore, MD, USA
}

\begin{abstract}
The prevalence of obesity worldwide has nearly doubled since 1980 with current estimates of 2.1 billion in 2013. Overweight and obesity lead to numerous adverse conditions including type 2 diabetes, cardiovascular disease, stroke, and certain cancers. The worldwide spread of obesity and associated comorbidities not only threatens quality of life but also presents a significant economic burden. While bariatric surgery has proven to be a viable treatment option for the morbidly obese, there is clearly a need for less invasive alternatives. Recent research has suggested that long-acting analogs of the gut hormone, glucagon-like peptide 1 (GLP-1), may have potential as an antiobesity treatment. The GLP-1 receptor agonist, liraglutide (trade name Saxenda), was recently approved by the US Food and Drug Administration as an obesity treatment option and shown in clinical trials to be effective in reducing and sustaining body weight loss. This review presents the basis for GLP-1-based therapies with a specific focus on animal and human studies examining liraglutide's effects on food intake and body weight.
\end{abstract}

Keywords: glucagon-like peptide 1, obesity, liraglutide, exenatide

\section{Introduction}

Epidemiological studies have estimated that rates of obesity worldwide have increased steadily between 1980 and 2013. In the US, over one third of adults and one sixth of children and adolescents are currently considered obese. ${ }^{1-4}$

Overweight and obesity are frequently coupled to other debilitating diseases such as type 2 diabetes, coronary heart disease, ischemic stroke, and several cancers. ${ }^{5-7}$ Particularly concerning is the increasing prevalence of pediatric obesity which has been linked not only to metabolic disorders and cardiovascular risk factors but also to psychiatric illness, early pubertal onset, and orthopedic disorders. ${ }^{8-11}$ Because of the comorbidities associated with increased body weight, obesity is considered to be a major public health concern with a significant economic burden to our health care system. It has been projected that by 2030 , costs associated with overweight and obesity will comprise $16 \%-18 \%$ of total health care expenses in the US. ${ }^{3,12}$

Surgical interventions, such as Roux-en-Y gastric bypass and sleeve gastrectomy, have been highly successful in promoting weight loss and correcting accompanying comorbidities like diabetes. ${ }^{13,14}$ However, due to the risks associated with surgery, particularly in a vulnerable population, surgical interventions are often considered to be a last resort and reserved for those patients who are morbidly obese or have failed at other weight loss strategies. Clearly, there is a need for less invasive means to achieve sustainable weight loss in patients who are not prime candidates for bariatric surgery or desire nonsurgical alternatives.

A number of pharmacological interventions have been marketed for weight loss with mixed or limited success. Appetite suppressants, such as phentermine, were initially approved by the US Food and Drug Administration (FDA) in the 1950s for 
short-term use for weight loss; however, limited data are available to support their long-term efficacy. More recently, a combination drug consisting of phentermine and topiramate (marketed as Qsymia) was approved by the FDA for longer term use and shown to produce approximately $10 \%$ loss in body weight as well as improvements in glucose levels, blood pressure, cholesterol, and other cardiovascular risk factors after 2 years of treatment. ${ }^{15,16}$

Orlistat (trade name Xenical) was approved for use by the FDA in 1999 as a long-term treatment for weight loss and acts by interfering with pancreatic lipase, thereby decreasing the absorption of dietary fat. It is currently the only obesity medication that is approved in Europe. Results from clinical trials with orlistat have reported only modest weight loss (5-7 pounds) after continued use, though significant improvements were noted for several cardiovascular risk factors including decreased blood pressure and improved glucose tolerance. ${ }^{17-19}$ Other drugs approved by the FDA for chronic weight management are lorcasersin (trade name Belviq), ${ }^{20}$ a selective serotonin-2C receptor agonist, and the combination drug naltrexone/bupropion (trade name Contrave), ${ }^{21-23}$ both of which are proposed to reduce food intake by acting through the hypothalamic melanocortin system. $^{22}$ The latter is currently being considered for approval by the European Medicines Agency (EMA) under the trade name Mysimba.

Analogs of the incretin hormone, glucagon-like peptide 1 (GLP-1), have recently been introduced as potential weight loss medications. These analogs were initially used as drugs for the treatment of type 2 diabetes; however, results from clinical trials have repeatedly demonstrated their ability to induce weight loss. ${ }^{24}$ One of these medications that has been approved by the EMA and FDA for the treatment of diabetes is liraglutide, a long-acting GLP-1 receptor agonist developed by Novo Nordisk, and a number of trials have reported positive results on its efficacy to improve indices of glycemic and cardiovascular risk factors.

On December 23, 2014, the FDA announced approval of a higher dose version of liraglutide (trade name Saxenda) for the treatment of chronic weight management. This drug was approved for adults with a body mass index (BMI) of 30 or higher or those with a BMI of 27 or higher who have at least one weight-related comorbid condition such as hypertension, type 2 diabetes, or elevated cholesterol.

This review provides an overview of GLP-1 and GLP-1 receptor agonists in animal and human studies, with particular emphasis on liraglutide, and discusses their therapeutic potential for obesity treatment.

\section{GLP-I and GLP-I analogs}

GLP-1 is derived from posttranslational processing of the preproglucagon gene and subsequently cleaved into its biologically active forms, GLP-1 (7-36) amide which comprises approximately $80 \%$ of circulating GLP-1 and GLP-1 (7-37). ${ }^{25,26}$ GLP-1 is secreted from endocrine L cells in the distal intestinal mucosa primarily in response to the presence of nutrients in the intestinal lumen. Once in circulation, the half-life of GLP-1 is less than 2 minutes due to rapid degradation by the enzyme dipeptidyl peptidase-IV (DPP-IV). ${ }^{27,28}$

GLP-1 is classified as an incretin hormone because it stimulates a decrease in blood glucose levels by increasing the amount of insulin released from pancreatic beta cells after eating, prior to the elevation of blood glucose levels. ${ }^{29}$ GLP-1 is also effective in controlling blood glucose because it suppresses glucagon secretion and slows gastric emptying. ${ }^{30}$ Because of GLP-1's effects on glucose homeostasis, it was an attractive target for drug development in the treatment of type 2 diabetes.

GLP-1 has a very short half-life in circulation, and therefore, its utility as a therapeutic agent in the treatment of diabetes was limited. The peptide, exendin-4, is a 39-amino acid naturally occurring peptide with 53\% homology to native GLP-1 that was originally isolated from the saliva of the Gila monster. It was found to exhibit glucose regulatory properties similar to GLP-1 but resisted degradation by DPP-IV. Its synthetic version, exenatide, was approved by the FDA in 2005 and in Europe in 2006 as an adjunct therapy for patients with type 2 diabetes who failed to respond to metformin or sulfonylureas. ${ }^{31}$ It is administered as a subcutaneous injection either twice daily (Byetta) or in a more recently approved sustained-release weekly formulation (Bydureon). While it was initially marketed as a diabetes drug, clinical trials consistently found significant reductions in body weight due to its appetite-suppressing effects. ${ }^{32}$ Several other GLP-1 analogs are currently under investigation or are approved for the treatment of type 2 diabetes. These include lixsenatide (Sanofi Aventis, trade name Lyxumia) and albiglutide (GlaxoSmithKline, trade names Epezan and Tanseum) which have amino acid modifications to resist degradation by DPP-IV. The recently FDA-approved drug, dulaglutide (Eli Lilly, trade name Trulicity), an analog of human GLP-1, is covalently linked to an Fc fragment of human IgG4 enabling it to resist degradation and reduce renal clearance. ${ }^{33-35}$

Liraglutide, another long-acting GLP-1 receptor agonist, was developed by Novo Nordisk and marketed under the brand name Victoza. It shares 97\% structural homology 
with human GLP-1 and has a half-life of 10-14 hours. The longer half-life is due to a modification of the peptide with an amino acid substitution and the addition of a fatty acid chain that allows it to bind to circulating plasma proteins, thus slowing absorption and rendering it resistant to degradation. ${ }^{36}$ It was approved for use by the EMA in 2009 and by the FDA in 2010 as a diabetes medication that is administered by once-daily subcutaneous injection as a monotherapy or in combination with other diabetes medications. In a study comparing exenatide and liraglutide, it was found that liraglutide was superior to exenatide in reducing $\mathrm{HbA}_{1 c}$, systolic blood pressure, fasting blood glucose, and triglycerides and free fatty acids (Liraglutide Effect and Action in Diabetes-6 trial) with fewer undesirable side effects. ${ }^{37}$

\section{Effects of liraglutide on food intake and body weight: animal studies}

As mentioned above, GLP-1 is secreted from endocrine ( $\mathrm{L}$ cells) in the intestinal mucosa primarily in the ileum and distal colon. Besides its presence in the gastrointestinal tract, GLP-1 is found in the central nervous system localized to neurons primarily in the nucleus of the solitary tract (NTS) in the caudal brainstem. ${ }^{38}$ Neurons in the NTS that express GLP-1 send projections to several brain regions that participate in feeding behavior and energy homeostasis. ${ }^{38-40}$

GLP-1's actions are mediated through the G-proteincoupled GLP-1 receptor. In the rodent, high-affinity binding sites for GLP-1 are found in the pancreas, enteric nerves, vagus nerve, heart, kidney, and adipose tissue.$^{41-43}$ In the brain, GLP-1 receptor mRNA is distributed in many brain areas associated with food intake and body weight including the arcuate and dorsomedial nuclei of the hypothalamus, parabrachial nuclei, nucleus accumbens (NAc), NTS, and area postrema. ${ }^{44}$

Numerous studies have demonstrated that systemic administration of GLP-1 or GLP-1 receptor agonists decreases food intake, slows gastric emptying, and reduces body weight. ${ }^{45-49}$ Blockade of peripheral GLP-1 receptors by the selective receptor antagonist, exendin (9-39), attenuated the reduction of food intake produced by voluntary consumption of a sucrose meal and by prior administration of GLP-1. The same reversal in the food intake suppression was not seen after central administration of exendin (9-39) supporting the interpretation that peripheral, not central, GLP-1 receptors were mediating the effects on food intake. ${ }^{48}$ Further studies examining the neural pathways responsible for these effects have shown that severing the connection between the gastrointestinal tract and the brain by total subdiaphragmatic vagotomy, or by chemical vagal deafferentation, prevented the suppression of food intake produced by GLP-1 receptor activation. ${ }^{50,51}$ Together, these studies support a role for peripheral GLP-1 as a physiological satiety signal.

While these studies implicate peripheral GLP-1 in ingestive control, there is also substantial evidence to support a role for central GLP-1 signaling in food intake and body weight regulation. Early studies reported that third intracerebroventricular (icv) administration of GLP-1 significantly reduced food intake and body weight, whereas administration of the GLP-1 receptor antagonist exendin (9-39) increased food intake and body weight. ${ }^{47,52}$ While there has been much debate about whether GLP-1 acts primarily at a peripheral or central site, there are now sufficient data to support the view that GLP-1 may have multiple actions that include both peripheral and central GLP-1 receptor populations. ${ }^{49,53}$

While most studies have used exendin-4 as an experimental tool to activate GLP-1 receptors, the availability of newly developed long-acting agonists such as liraglutide has prompted investigations to determine if they share similar biological activity. A study comparing the efficacy of peripheral administration of liraglutide and exendin-4 to decrease food intake and body weight in nonobese rats reported that once-daily administration of both agonists produced a dose-dependent reduction in chow intake; however, only liraglutide reduced body weight. ${ }^{54}$ The effects of liraglutide on food intake and body weight were greater in magnitude and latency when given by intraperitoneal compared to subcutaneous injection. The same study reported that in diet-induced obese rats fed a palatable high-fat/high-sugar diet, chronic 7-day peripheral delivery of exendin-4 and liraglutide elicited equivalent reductions in food intake and weight loss over the test period.

A similar comparative study was also conducted to examine the anorectic effects of centrally administered liraglutide and exendin- 4 in rats. ${ }^{55}$ The data demonstrated that the icv dosage of liraglutide needed to suppress food intake and induce the same degree of hypothalamic c-fos activation (a marker of neuronal activity) was tenfold greater than equivalent feeding suppression and c-fos activation following exendin-4. When animals were pretreated centrally with the GLP-1 receptor antagonist, exendin (9-36), the suppression of food intake by both agonists was blocked substantiating that the effects of both agonists were mediated through GLP-1 receptor activation.

Additional studies using both pharmacological and surgical methods were conducted to determine whether the site of action for peripheral administration of exendin-4 and liraglutide was localized to peripheral or central GLP-1 
receptors. ${ }^{56}$ The results from this study demonstrated that intraperitoneal administration of exendin (9-39) failed to block the effects of peripherally administered exendin-4 and liraglutide. By contrast, central administration of exendin (9-39) attenuated, but did not completely abolish, the suppression of food intake by both exendin-4 and liraglutide and reversed the body weight change seen with liraglutide. Although animals with selective vagal deafferentation still suppressed intake after GLP-1 receptor agonist administration, higher doses were required. Together, these studies suggest that peripheral administration of exendin-4 and liraglutide produce their feeding and weight loss effects at both central and peripheral GLP-1 receptors. The findings are in contrast to those reported for GLP- $1^{48}$ and suggest that the mechanisms through which long-acting GLP-1 receptor agonists produce their effects on food intake and body weight are not identical to those of native GLP-1. This difference is likely due to the longer half-life of GLP-1 analogs resulting in sustained peripheral physiological effects. Furthermore, there is evidence that these compounds are capable of diffusing across the blood-brain barrier and thereby stimulating central GLP-1 receptors. ${ }^{57}$

The mechanism(s) by which long-acting GLP-1 receptor agonists reduce food intake and body weight is actively under investigation. One potential mechanism for reducing body weight is through GLP-1's effects on energy expenditure. Central injection of liraglutide in rodents stimulates brown-fat thermogenesis and induces browning of white adipose tissue independent of its ability to suppress food intake. ${ }^{58}$ Site-specific injections of liraglutide into various hypothalamic nuclei identified the ventromedial hypothalamus (VMH) as mediating this effect. Since AMPK within the VMH has been implicated in brown adipose tissue thermogenesis, the importance of AMPK in the mediation of liraglutide-induced brown adipose tissue thermogenesis was also evaluated. This study found that icv administration of AICAR, a pharmacological activator of AMPK, had no effect on the ability of icv liraglutide to reduce food intake but prevented the reduction in body weight produced by liraglutide. Furthermore, liraglutide injected into the VMH produced weight loss that was completely blocked by overexpression of constitutively active AMPK. Activation of AMPK in the VMH decreased liraglutide-induced UCP1 expression in adipose tissue supporting the view that AMPK in the VMH participates in the actions of central GLP-1 on brown and white adipose tissue.

In a series of studies designed to evaluate the site of action of liraglutide-induced weight loss, it was demonstrated that the arcuate nucleus in the hypothalamus plays a critical role. ${ }^{57}$ Rats that underwent subdiaphragmatic vagal deafferentation reduced body weight to the same extent as sham-operated controls after a 14-day regimen of liraglutide (twice-daily subcutaneous injections, $200 \mathrm{~g} / \mathrm{kg}$ ) indicating that the weightreducing effects of liraglutide are not dependent upon an intact afferent vagus nerve. Similarly, liraglutide treatment produced weight loss to the same degree in animals with lesions of the hindbrain area postrema compared to those with sham lesions. However, long-term liraglutide treatment significantly increased expression of cocaine and amphetaminerelated transcript but did not increase neuropeptide Y (NPY)/ agouti-related protein (AgRP) gene expression in the arcuate nucleus suggesting that liraglutide prevents the normal activation of the NPY/AgRP system to increase food intake during periods of weight loss. Preventing the normal stimulation of food intake by NPY/AgRP that occurs during energy deficit would benefit sustained decreases in body weight.

In a follow-up study, fluorescently labeled liraglutide was used to determine if peripherally administered liraglutide could directly access brain regions that might be involved in its effects on food intake and body weight. Labeled liraglutide was detected in all circumventricular organs and several hypothalamic nuclei including the arcuate nucleus. Surprisingly, the NTS was devoid of a fluorescent signal, a brain region strongly implicated in GLP-1's effects on food intake. This would suggest that if the NTS is involved in the effects of liraglutide on body weight, it may be through an indirect, rather than a direct, activation of GLP-1 receptors. Despite this, numerous animal studies have implicated the NTS as mediating the effects of GLP-1 receptor stimulation, and studies have demonstrated that peripheral treatment with liraglutide can produce a conditioned taste aversion and transient pica, two rodent models of nausea which are proposed to be mediated by NTS GLP-1 receptors. ${ }^{59-62}$

Other mechanisms by which liraglutide suppresses food intake and body weight have also been evaluated. As mentioned, GLP-1 receptor agonists have potent effects on gastric emptying which could contribute to their feeding inhibitory effects. Doses of exenatide and liraglutide that produce equivalent reductions in food intake significantly delay gastric emptying. It was shown that the effects on gastric emptying were markedly decreased following long-term (14-day) treatment with liraglutide but remained the same with exenatide treatment. Because weight loss was similar between the two treatment groups, this suggests that suppression of gastric emptying did not contribute significantly to the weight loss produced by liraglutide. ${ }^{63}$

Recent neuroanatomical and behavioral evidence also support a role for GLP-1 in reward and motivation. ${ }^{64,65}$ GLP-1 neurons in the NTS project to reward-associated brain areas 
such as the ventral tegmental area (VTA) and NAc. ${ }^{39,40,66-68}$ GLP-1 analogs injected directly into the NAc have been demonstrated to decrease intake of high-fat and high-sucrose diets, presumably by reducing their palatability. ${ }^{40,68}$ A link between peripheral nutrient-related signals and central GLP-1's effects on reward processing was supported by data showing that the suppression of meal intake following an intestinal infusion of $40 \%$ sucrose could be attenuated by blockade of NAc GLP-1 receptors. ${ }^{68}$ A role for the GLP-1 NTS neuronal projection to the VTA in food intake has also been suggested in an animal study showing that intra-VTA injection of exendin-4 reduced intake of both chow and highfat diet, while blockade of VTA GLP-1 receptors increased high-fat food intake, proposed to be mediated, in part, through VTA dopamine signaling. ${ }^{39}$

Several lines of evidence support the view that liraglutide, like exendin-4, may act via mechanisms that alter the rewarding properties of food. Studies to evaluate dietary effects on the ability of liraglutide to inhibit food intake have shown that rats maintained on a high-fat diet exhibited a delayed response to the anorectic effects of peripherally administered liraglutide. However, once intake was suppressed, it was sustained for a longer period of time compared to animals on a low-fat diet. ${ }^{69}$ When diet-obese animals were treated with liraglutide and allowed a choice between a highly palatable diet and chow, their preference shifted toward decreasing intake of the palatable diet and increasing intake of chow. ${ }^{70,71}$ This feature was not shared with either the DPP-IV inhibitor, vildagliptin, which increases postprandial GLP-1, or sibutramine, a 5HT agonist/reuptake inhibitor, which causes similar reductions in body weight. ${ }^{70,71}$

Because evidence suggests that GLP-1 affects food intake through both energy homeostatic and reward mechanisms, GLP-1 receptor agonist medications, such as liraglutide, offer a multi-pronged approach for promoting weight loss. A recent study in rats examined the effects of combining low doses of leptin and liraglutide and demonstrated greater weight loss with the combination treatment than with either drug given alone. ${ }^{72}$ As well, diet-induced obese mice that were chronically treated with liraglutide and a melanocortin-4 receptor agonist exhibited greater weight loss and improved glycemic control and cholesterol metabolism than that achieved with each treatment alone. ${ }^{73}$ These findings support further exploration into the feasibility of combinatorial therapies that may produce greater weight loss with less possibility of adverse events. Animal studies with GLP-1 receptor agonists will provide critical insights into mechanisms of action that could be utilized to enhance or tailor treatment regimens to more effectively promote weight loss in humans.

\section{Effects of liraglutide on food intake and body weight: human studies}

Liraglutide was first approved for the treatment of diabetes after studies were conducted in a large population of subjects and found that it improved glycemic control and produced significant body weight loss with limited side effects. Subsequently, additional long-term (2-year) studies were conducted to examine safety and tolerability as a primary outcome and address issues of sustainability of weight loss as a secondary outcome. ${ }^{74,75}$ These measures were compared with those from individuals who received the fat-blocking drug, orlistat. The results indicated that weight loss was significantly greater in the group that received liraglutide compared with the group that received orlistat. Body composition data revealed that the primary reduction came from a loss of body fat of approximately $15 \%$. Systolic and diastolic blood pressure was significantly decreased in both groups but significantly lower in the liraglutide group after the 2-year treatment period. The primary outcome measures of safety and tolerability found several self-reported cases of symptomatic hypoglycemia; however, the majority of drug-related side effects attributed to liraglutide were transient nausea and vomiting. The general conclusion was that the drug was well tolerated over extended treatment periods and was effective in sustaining weight loss and improving cardiovascular risk factors. Similar results were reported in a 2-year study examining liraglutide's effects on body weight and glycemic control in Japanese type 2 diabetic subjects ${ }^{76}$ and in a study showing that liraglutide $(3.0 \mathrm{mg} /$ day $)$ in combination with a low-calorie diet and physical activity resulted in significantly greater weight loss in overweight and obese adults with type 2 diabetes than in those receiving placebo. ${ }^{77}$

A large multisite randomized trial (DURATION-6) was conducted to compare the effects of sustained-release exenatide once weekly to liraglutide $(1.8 \mathrm{mg} /$ day) once daily in patients with type 2 diabetes. ${ }^{78}$ The major outcome measure was a change in $\mathrm{HbA}_{1 \mathrm{c}}$, an indicator of blood glucose concentration; however, other secondary outcomes including changes in body weight, fasting blood glucose, and blood pressure were also examined. It was demonstrated that while both GLP-1 analogs improved glycemic control and produced weight loss, the improvements in $\mathrm{HbA}_{1 \mathrm{c}}$ and body weight reduction were greater in the liraglutide group. Both groups had similar improvements in blood pressure and other cardiovascular biomarkers.

While generally well tolerated, several side effects of GLP-1 agonists have been reported. The most frequent of these is nausea which is more problematic in the early stages of treatment and with shorter acting agonists such as exenatide 
due to higher peak concentrations than those produced with slow-release GLP-1 agonists. ${ }^{37,78,79}$ Other gastrointestinal complaints such as vomiting and diarrhea have also been reported, though with less frequency than nausea. ${ }^{37,78,80}$ While these side effects do not represent serious health issues, they may contribute to a patient's decision to discontinue therapy.

Other side effects include a small (2-4 beats/min) but sustained increase in heart rate. Despite this, preclinical studies have reported that GLP-1 agonists have a beneficial effect on cardiovascular outcomes. ${ }^{81}$ Additionally, since GLP-1 receptor agonists induce pancreatic beta-cell proliferation, there is the possibility that long-term use could result in pancreatitis. However, in clinical trials evaluating approximately 4,500 patients, seven cases of pancreatitis were reported which was not beyond expected rates for this population, and reviews of clinical data by the EMA concluded that GLP-1 agonist treatments did not pose an increased risk for the development of pancreatitis. ${ }^{82}$ Some concerns were also raised about the potential risk of thyroid cancer based on animal studies demonstrating proliferation of thyroid C-cells and tumor formation in rodents following long-term treatment with GLP-1 agonist compounds. ${ }^{83}$ This finding was not consistent with data obtained from nonhuman primates who, like humans, exhibit a much lower density of GLP-1 receptors on thyroid C cells. ${ }^{84}$ Nevertheless, the effects of prolonged use of higher doses of liraglutide such as those used for weight loss treatment in humans have not been determined.

Although many studies have reported significant effects of liraglutide on body weight loss, there are limited data available that specifically evaluate the possible mechanisms underlying liraglutide's effects on body weight in humans. To address this, a recent study of obese individuals, without diabetes, examined the effects of once-daily administration of liraglutide on several parameters that may contribute to weight loss, including gastric emptying, glycemic control, appetite, and energy metabolism. ${ }^{85}$ Subjects received $1.8 \mathrm{mg}$ (the dose currently approved for diabetes treatment), $3.0 \mathrm{mg}$ (the dose currently approved for weight loss), or a placebo. After 5 weeks of treatment, the effects on gastric emptying of a test meal were found to be equivalent for the two doses of liraglutide and for liraglutide versus placebo for the duration of the 5-hour testing period; however, early ( $1 \mathrm{~h}$ ) gastric emptying was significantly delayed with the $3.0 \mathrm{mg}$ liraglutide dose. In addition to evaluating the effects of liraglutide on gastric emptying, subjects were asked to consume a lunch meal ad libitum to determine energy intake and to assess feelings of satiety, fullness, and hunger. The study found that both doses of liraglutide equivalently reduced energy intake which was accompanied by increased postprandial satiety and fullness ratings and a decrease in hunger ratings. All groups had reduced 24-hour energy expenditure which was greater for liraglutide versus placebo, a difference that was attributed to a decrease in body weight. A shift toward increased fat oxidation and decreased carbohydrate oxidation was noted in the group receiving liraglutide. Measures of glycemic control were also found to be significantly improved in both liraglutide treatment groups. The conclusion from these data was that the mechanism responsible for weight loss induced by liraglutide was due to a long-term reduction in appetite and food intake, as opposed to effects on energy expenditure. As mentioned above, experiments in rodents have shown that repeated doses of liraglutide result in a diminished ability to delay gastric emptying; ${ }^{63}$ however, this does not appear to be the case in humans, since there were still significant effects on emptying at the earlier time points with the highest dose. Thus, delays in gastric emptying may partially contribute to the reduction in meal intake produced by liraglutide in humans.

While the van Can et al study ${ }^{85}$ examined liraglutide's effects in obese subjects without diabetes, similar parameters were also evaluated in obese subjects with diabetes. The results in diabetic subjects were in general agreement with liraglutide's effects on weight loss, satiety, gastric emptying, and energy expenditure in nondiabetic subjects. ${ }^{86}$ The failure of this, and other studies, to observe significant changes in energy expenditure after GLP-1 analog administration is in contrast to recent data demonstrating an increase in resting energy expenditure in obese type 2 diabetic patients. ${ }^{58}$ The discrepancy in these results may be due, in part, to the increased length of treatment in this study in which patients were treated for 1 year with GLP-1 receptor agonists.

As in rodent studies, it has been postulated that GLP-1 receptor agonists may reduce food intake in humans by modulating the rewarding properties of food. In a study using functional magnetic resonance imaging, obese type 2 diabetic patients exhibited increased brain responses to pictures of food in reward and appetite-related brain regions compared to lean control subjects. The enhanced response to food-related images in obese subjects was blocked by administration of a GLP-1 receptor antagonist, supporting the view that GLP-1 agonists such as liraglutide may promote weight loss by reducing the hyperresponsiveness to food cues to a pattern that is consistent with that of lean individuals. ${ }^{65}$

An interaction between the adipose-derived peptide, leptin, and GLP-1 has been demonstrated in experiments in rodents showing that subthreshold doses of leptin increased the ability of GLP-1 inhibit food intake. ${ }^{87}$ Furthermore, GLP-1 
receptor agonists can reinstate leptin sensitivity in obese animals. ${ }^{88,89}$ As in animals, obese humans have high levels of circulating leptin but are leptin resistant and therefore do not respond appropriately to this signal to reduce energy intake. During weight loss, a drop in plasma leptin levels that results from decreased fat mass produces a rebound response that favors increased food intake. Based on animal studies, it was postulated that administration of a GLP-1 receptor agonist during diet-induced weight loss would inhibit decreases in soluble leptin receptor plasma concentrations (one marker for leptin activity) caused by decreased adiposity and thus prevent a regain in body weight. ${ }^{90}$ This study demonstrated that liraglutide ( $1.2 \mathrm{mg} /$ day) inhibited the increase in soluble leptin receptor that is normally seen in individuals undergoing weight loss. Consequently, free leptin levels were increased, thereby providing a signal that would prevent an increase in food intake and a decrease in energy expenditure. Supporting the hypothesis, the results indicated that the group receiving the liraglutide, in conjunction with reduced caloric intake, had greater weight loss during the maintenance period than the group that did not receive liraglutide. This study has important implications for the potential use of liraglutide as an adjunct to more traditional weight loss regimens and for the long-term sustainability of weight loss treatments. Additionally, it suggests another avenue through which GLP-1 receptor agonists contribute to weight loss.

\section{Conclusion}

In summary, the GLP-1 receptor agonist, liraglutide, has been demonstrated to reduce food intake, promote weight loss, and improve indices of metabolic function in both animal and human studies. The primary mechanisms associated with these effects are proposed to be due to actions of GLP-1 on peripheral (vagal) and central pathways that affect food intake and metabolism via hindbrain and hypothalamic activation, as well as those brain areas associated with motivation and reward processes.

With the high prevalence of obesity and its negative impact on quality of life, there is a critical need for therapies that will produce a sustainable loss of body weight. Currently, the most effective treatment option is bariatric surgery. A recent comparison between the clinical efficacy of bariatric surgery and liraglutide found surgery to be superior to liraglutide for both body weight reduction and improvements in metabolic parameters. ${ }^{91}$ Despite this, many individuals are not ideal candidates for surgery and would benefit from noninvasive medical treatments. Liraglutide has been demonstrated to produce significant weight loss in humans, with and without type 2 diabetes, while producing minimal side effects and thus is an attractive treatment option. Additional research is warranted for its potential in combinatorial weight loss treatments that may further enhance and sustain weight loss.

\section{Disclosure}

The author reports no conflicts of interest in this work.

\section{References}

1. Flegal KM, Carroll MD, Ogden CL, Curtin LR. Prevalence and trends in obesity among US adults, 1999-2008. JAMA. 2010;303(3):235-241.

2. Ogden CL, Carroll MD, Curtin LR, Lamb MM, Flegal KM. Prevalence of high body mass index in US children and adolescents, 2007-2008. JAMA. 2010;303(3):242-249.

3. Wang YC, McPherson K, Marsh T, Gortmaker SL, Brown M. Health and economic burden of the projected obesity trends in the USA and the UK. Lancet. 2011;378(9793):815-825.

4. Ng M, Fleming $\mathrm{T}$, Robinson $\mathrm{M}$, et al. Global, regional, and national prevalence of overweight and obesity in children and adults during 1980-2013: a systematic analysis for the global burden of disease study 2013. Lancet. 2014;384(9945):766-781.

5. Guh DP, Zhang W, Bansback N, Amarsi Z, Birmingham CL, Anis AH. The incidence of co-morbidities related to obesity and overweight: a systematic review and meta-analysis. BMC Public Health. 2009;9:88.

6. Renehan AG, Tyson M, Egger M, Heller RF, Zwahlen M. Body-mass index and incidence of cancer: a systematic review and meta-analysis of prospective observational studies. Lancet. 2008;371(9612):569-578.

7. de Groot PC, Dekkers OM, Romijn JA, Dieben SW, Helmerhorst FM PCOS, coronary heart disease, stroke and the influence of obesity: a systematic review and meta-analysis. Hum Reprod Update. 2011; 17(4):495-500.

8. Weiss R, Dziura J, Burgert TS, et al. Obesity and the metabolic syndrome in children and adolescents. N Engl J Med. 2004;350(23):2362-2374.

9. Burt Solorzano CM, McCartney CR. Obesity and the pubertal transition in girls and boys. Reproduction. 2010;140(3):399-410.

10. Esposito M, Gallai B, Roccella M, et al. Anxiety and depression levels in prepubertal obese children: a case-control study. Neuropsychiatr Dis Treat. 2014;10:1897-1902.

11. Gettys FK, Jackson JB, Frick SL. Obesity in pediatric orthopaedics. Orthop Clin North Am. 2011;42(1):95-105,vii.

12. Wang Y, Beydoun MA, Liang L, Caballero B, Kumanyika SK. Will all Americans become overweight or obese? estimating the progression and cost of the US obesity epidemic. Obesity (Silver Spring). 2008; 16(10):2323-2330.

13. Courcoulas AP, Yanovski SZ, Bonds D, et al. Long-term outcomes of bariatric surgery: a National Institutes of Health Symposium. JAMA Surg. 2014;149(12):1323-1329.

14. Svane MS, Bojsen-Moller KN, Madsbad S, Holst JJ. Updates in weight loss surgery and gastrointestinal peptides. Curr Opin Endocrinol Diabetes Obes. 2015;22(1):21-28.

15. Bray GA, Ryan DH. Update on obesity pharmacotherapy. Ann NY Acad Sci. 2014;1311:1-13.

16. Garvey WT, Ryan DH, Look M, et al. Two-year sustained weight loss and metabolic benefits with controlled-release phentermine/ topiramate in obese and overweight adults (SEQUEL): a randomized, placebo-controlled, phase 3 extension study. Am J Clin Nutr. 2012;95(2):297-308.

17. Bakris G, Calhoun D, Egan B, Hellmann C, Dolker M, Kingma I. Orlistat improves blood pressure control in obese subjects with treated but inadequately controlled hypertension. J Hypertens. 2002; 20(11):2257-2267.

18. Zavoral JH. Treatment with orlistat reduces cardiovascular risk in obese patients. J Hypertens. 1998;16(12 pt 2):2013-2017. 
19. Derosa G, Maffioli P, Salvadeo SA, et al. Comparison of orlistat treatment and placebo in obese type 2 diabetic patients. Expert Opin Pharmacother. 2010;11(12):1971-1982.

20. Smith SR, Prosser WA, Donahue DJ, Morgan ME, Anderson CM, Shanahan WR. Lorcaserin (APD356), a selective 5-HT(2C) agonist, reduces body weight in obese men and women. Obesity (Silver Spring). 2009;17(3): 494-503.

21. Caixas A, Albert L, Capel I, Rigla M. Naltrexone sustained-release/ bupropion sustained-release for the management of obesity: review of the data to date. Drug Des Devel Ther. 2014;8:1419-1427.

22. Greenway FL, Whitehouse MJ, Guttadauria M, et al. Rational design of a combination medication for the treatment of obesity. Obesity (Silver Spring). 2009;17(1):30-39.

23. Greenway FL, Fujioka K, Plodkowski RA, et al; COR-I Study Group. Effect of naltrexone plus bupropion on weight loss in overweight and obese adults (COR-I): a multicentre, randomised, double-blind, placebocontrolled, phase 3 trial. Lancet. 2010;376(9741):595-605.

24. Monami M, Dicembrini I, Marchionni N, Rotella CM, Mannucci E. Effects of glucagon-like peptide-1 receptor agonists on body weight: a meta-analysis. Exp Diabetes Res. 2012;2012:672658.

25. Holst JJ. The physiology of glucagon-like peptide 1. Physiol Rev. 2007; 87(4):1409-1439.

26. Orskov C, Rabenhoj L, Wettergren A, Kofod H, Holst JJ. Tissue and plasma concentrations of amidated and glycine-extended glucagon-like peptide I in humans. Diabetes. 1994;43(4):535-539.

27. Kieffer TJ, McIntosh CH, Pederson RA. Degradation of glucosedependent insulinotropic polypeptide and truncated glucagon-like peptide 1 in vitro and in vivo by dipeptidyl peptidase IV. Endocrinology. 1995;136(8):3585-3596.

28. Holst JJ, Deacon CF. Glucagon-like peptide-1 mediates the therapeutic actions of DPP-IV inhibitors. Diabetologia. 2005;48(4):612-615.

29. Orskov C, Wettergren A, Holst JJ. Secretion of the incretin hormones glucagon-like peptide-1 and gastric inhibitory polypeptide correlates with insulin secretion in normal man throughout the day. Scand $J$ Gastroenterol. 1996;31(7):665-670.

30. Wettergren A, Schjoldager B, Mortensen PE, Myhre J, Christiansen J, Holst JJ. Truncated GLP-1 (proglucagon 78-107-amide) inhibits gastric and pancreatic functions in man. Dig Dis Sci. 1993;38(4): 665-673.

31. Zinman B, Gerich J, Buse JB, et al; LEAD-4 Study Investigators. Efficacy and safety of the human glucagon-like peptide-1 analog liraglutide in combination with metformin and thiazolidinedione in patients with type 2 diabetes (LEAD-4 Met+TZD). Diabetes Care. 2009;32(7): 1224-1230.

32. Aroda VR, Henry RR, Han J, et al. Efficacy of GLP-1 receptor agonists and DPP-4 inhibitors: meta-analysis and systematic review. Clin Ther. 2012;34(6):1247-58e22.

33. Bain SC. The clinical development program of lixisenatide: a once-daily glucagon-like peptide-1 receptor agonist. Diabetes Ther. 2014;5(2): 367-383.

34. Pratley RE, Nauck MA, Barnett AH, et al; HARMONY 7 Study Group. Once-weekly albiglutide versus once-daily liraglutide in patients with type 2 diabetes inadequately controlled on oral drugs (HARMONY 7): a randomised, open-label, multicentre, non-inferiority phase 3 study. Lancet Diabetes Endocrinol. 2014;2(4):289-297.

35. Edwards KL, Minze MG. Dulaglutide: an evidence-based review of its potential in the treatment of type 2 diabetes. Core Evid. 2015;10:11-21.

36. Knudsen LB, Nielsen PF, Huusfeldt PO, et al. Potent derivatives of glucagon-like peptide-1 with pharmacokinetic properties suitable for once daily administration. J Med Chem. 2000;43(9):1664-1669.

37. Buse JB, Rosenstock J, Sesti G, et al; LEAD-6 Study Group. Liraglutide once a day versus exenatide twice a day for type 2 diabetes: a 26-week randomised, parallel-group, multinational, open-label trial (LEAD-6). Lancet. 2009;374(9683):39-47.

38. Larsen PJ, Tang-Christensen M, Holst JJ, Orskov C. Distribution of glucagon-like peptide-1 and other preproglucagon-derived peptides in the rat hypothalamus and brainstem. Neuroscience. 1997; 77(1):257-270.
39. Alhadeff AL, Rupprecht LE, Hayes MR. GLP-1 neurons in the nucleus of the solitary tract project directly to the ventral tegmental area and nucleus accumbens to control for food intake. Endocrinology. 2012; 153(2):647-658.

40. Dossat AM, Lilly N, Kay K, Williams DL. Glucagon-like peptide 1 receptors in nucleus accumbens affect food intake. J Neurosci. 2011; 31(41):14453-14457.

41. Vahl TP, Tauchi M, Durler TS, et al. Glucagon-like peptide-1 (GLP-1) receptors expressed on nerve terminals in the portal vein mediate the effects of endogenous GLP-1 on glucose tolerance in rats. Endocrinology. 2007;148(10):4965-4973.

42. Bullock BP, Heller RS, Habener JF. Tissue distribution of messenger ribonucleic acid encoding the rat glucagon-like peptide-1 receptor. Endocrinology. 1996;137(7):2968-2978.

43. Nakagawa A, Satake H, Nakabayashi H, et al. Receptor gene expression of glucagon-like peptide-1, but not glucose-dependent insulinotropic polypeptide, in rat nodose ganglion cells. Auton Neurosci. 2004;110(1):36-43.

44. Merchenthaler I, Lane M, Shughrue P. Distribution of pre-pro-glucagon and glucagon-like peptide-1 receptor messenger RNAs in the rat central nervous system. J Comp Neurol. 1999;403(2):261-280.

45. Marathe CS, Rayner CK, Jones KL, Horowitz M. Effects of GLP-1 and incretin-based therapies on gastrointestinal motor function. Exp Diabetes Res. 2011;2011:279530.

46. Dailey MJ, Moran TH. Glucagon-like peptide 1 and appetite. Trends Endocrinol Metab. 2013;24(2):85-91.

47. Turton MD, O'Shea D, Gunn I, et al. A role for glucagon-like peptide-1 in the central regulation of feeding. Nature. 1996;379(6560):69-72.

48. Williams DL, Baskin DG, Schwartz MW. Evidence that intestinal glucagon-like peptide-1 plays a physiological role in satiety. Endocrinology. 2009;150(4):1680-1687.

49. van Bloemendaal L, Ten Kulve JS, la Fleur SE, Ijzerman RG, Diamant M. Effects of glucagon-like peptide 1 on appetite and body weight: focus on the CNS. J Endocrinol. 2014;221(1):T1-T16.

50. Abbott CR, Monteiro M, Small CJ, et al. The inhibitory effects of peripheral administration of peptide YY(3-36) and glucagon-like peptide- 1 on food intake are attenuated by ablation of the vagalbrainstem-hypothalamic pathway. Brain Res. 2005;1044(1):127-131.

51. Talsania T, Anini Y, Siu S, Drucker DJ, Brubaker PL. Peripheral exendin-4 and peptide YY(3-36) synergistically reduce food intake through different mechanisms in mice. Endocrinology. 2005;146(9):3748-3756.

52. Meeran K, O'Shea D, Edwards CM, et al. Repeated intracerebroventricular administration of glucagon-like peptide-1-(7-36) amide or exendin-(9-39) alters body weight in the rat. Endocrinology. 1999;140(1):244-250.

53. Williams DL. Minireview: finding the sweet spot: peripheral versus central glucagon-like peptide 1 action in feeding and glucose homeostasis. Endocrinology. 2009;150(7):2997-3001.

54. Hayes MR, Kanoski SE, Alhadeff AL, Grill HJ. Comparative effects of the long-acting GLP-1 receptor ligands, liraglutide and exendin-4, on food intake and body weight suppression in rats. Obesity (Silver Spring). 2011;19(7):1342-1349.

55. Sisley S, Smith K, Sandoval DA, Seeley RJ. Differences in acute anorectic effects of long-acting GLP-1 receptor agonists in rats. Peptides. 2014;58:1-6.

56. Kanoski SE, Fortin SM, Arnold M, Grill HJ, Hayes MR. Peripheral and central GLP-1 receptor populations mediate the anorectic effects of peripherally administered GLP-1 receptor agonists, liraglutide and exendin-4. Endocrinology. 2011;152(8):3103-3112.

57. Secher A, Jelsing J, Baquero AF, et al. The arcuate nucleus mediates GLP-1 receptor agonist liraglutide-dependent weight loss. J Clin Invest. 2014;124(10):4473-4488

58. Beiroa D, Imbernon M, Gallego R, et al. GLP-1 agonism stimulates brown adipose tissue thermogenesis and browning through hypothalamic AMPK. Diabetes. 2014;63(10):3346-3358.

59. Hayes MR, Bradley L, Grill HJ. Endogenous hindbrain glucagonlike peptide-1 receptor activation contributes to the control of food intake by mediating gastric satiation signaling. Endocrinology. 2009; 150(6):2654-2659. 
60. Hayes MR, Leichner TM, Zhao S, et al. Intracellular signals mediating the food intake-suppressive effects of hindbrain glucagon-like peptide-1 receptor activation. Cell Metab. 2011;13(3):320-330.

61. Hayes MR, Skibicka KP, Grill HJ. Caudal brainstem processing is sufficient for behavioral, sympathetic, and parasympathetic responses driven by peripheral and hindbrain glucagon-like-peptide-1 receptor stimulation. Endocrinology. 2008;149(8):4059-4068.

62. Kanoski SE, Rupprecht LE, Fortin SM, De Jonghe BC, Hayes MR. The role of nausea in food intake and body weight suppression by peripheral GLP-1 receptor agonists, exendin-4 and liraglutide. Neuropharmacology. 2012;62(5-6):1916-1927.

63. Jelsing J, Vrang N, Hansen G, Raun K, Tang-Christensen M, Knudsen LB. Liraglutide: short-lived effect on gastric emptying - long lasting effects on body weight. Diabetes Obes Metab. 2012;14(6): 531-538.

64. Skibicka KP. The central GLP-1: implications for food and drug reward. Front Neurosci. 2013;7:181

65. van Bloemendaal L, IJzerman RG, Ten Kulve JS, et al. GLP-1 receptor activation modulates appetite- and reward-related brain areas in humans. Diabetes. 2014;63(12):4186-4196.

66. Mietlicki-Baase EG, Ortinski PI, Reiner DJ, et al. Glucagon-like peptide-1 receptor activation in the nucleus accumbens core suppresses feeding by increasing glutamatergic AMPA/kainate signaling. J Neurosci. 2014;34(20):6985-6992.

67. Mietlicki-Baase EG, Ortinski PI, Rupprecht LE, et al. The food intakesuppressive effects of glucagon-like peptide-1 receptor signaling in the ventral tegmental area are mediated by AMPA/kainate receptors. Am J Physiol Endocrinol Metab. 2013;305(11):E1367-E1374.

68. Dossat AM, Diaz R, Gallo L, Panagos A, Kay K, Williams DL. Nucleus accumbens GLP-1 receptors influence meal size and palatability. Am J Physiol Endocrinol Metab. 2013;304(12):E1314-E1320.

69. Mul JD, Begg DP, Barrera JG, et al. High-fat diet changes the temporal profile of GLP-1 receptor-mediated hypophagia in rats. Am J Physiol Regul Integr Comp Physiol. 2013;305(1):R68-R77.

70. Raun K, von Voss P, Gotfredsen CF, Golozoubova V, Rolin B, Knudsen LB. Liraglutide, a long-acting glucagon-like peptide-1 analog, reduces body weight and food intake in obese candy-fed rats, whereas a dipeptidyl peptidase-IV inhibitor, vildagliptin, does not. Diabetes. 2007;56(1):8-15.

71. Hansen G, Jelsing J, Vrang N. Effects of liraglutide and sibutramine on food intake, palatability, body weight and glucose tolerance in the gubra DIO-rats. Acta Pharmacol Sin. 2012;33(2):194-200.

72. Kanoski SE, Ong ZY, Fortin SM, Schlessinger ES, Grill HJ. Liraglutide, leptin and their combined effects on feeding: additive intake reduction through common intracellular signalling mechanisms. Diabetes Obes Metab. 2014;17(3):285-293.

73. Clemmensen C, Finan B, Fischer K, et al. Dual melanocortin-4 receptor and GLP-1 receptor agonism amplifies metabolic benefits in dietinduced obese mice. EMBO Mol Med. 2015;7(3):288-298.

74. Astrup A, Carraro R, Finer N, et al; NN8022-1807 Investigators. Safety, tolerability and sustained weight loss over 2 years with the once-daily human GLP-1 analog, liraglutide. Int J Obes (Lond). 2012; 36(6):843-854.

75. Lean ME, Carraro R, Finer N, et al; NN8022-1807 Investigators. Tolerability of nausea and vomiting and associations with weight loss in a randomized trial of liraglutide in obese, non-diabetic adults. Int J Obes (Lond). 2014;38(5):689-697.
76. Inoue K, Maeda N, Fujishima Y, et al. Long-term impact of liraglutide, a glucagon-like peptide-1 (GLP-1) analogue, on body weight and glycemic control in Japanese type 2 diabetes: an observational study. Diabetol Metab Syndr. 2014;6(1):95.

77. Wadden TA, Hollander P, Klein S, et al; NN8022-1923 Investigators. Weight maintenance and additional weight loss with liraglutide after low-calorie-diet-induced weight loss: the SCALE maintenance randomized study. Int J Obes (Lond). 2015;39(1):187.

78. Buse JB, Nauck M, Forst T, et al. Exenatide once weekly versus liraglutide once daily in patients with type 2 diabetes (DURATION-6) a randomised, open-label study. Lancet. 2013;381(9861):117-124.

79. DeFronzo RA, Ratner RE, Han J, Kim DD, Fineman MS, Baron AD Effects of exenatide (exendin-4) on glycemic control and weight over 30 weeks in metformin-treated patients with type 2 diabetes. Diabetes Care. 2005;28(5):1092-1100.

80. Drucker DJ, Buse JB, Taylor K, et al; DURATION-1 Study Group. Exenatide once weekly versus twice daily for the treatment of type 2 diabetes: a randomised, open-label, non-inferiority study. Lancet. 2008;372(9645):1240-1250.

81. Ban K, Hui S, Drucker DJ, Husain M. Cardiovascular consequences of drugs used for the treatment of diabetes: potential promise of incretinbased therapies. J Am Soc Hypertens. 2009;3(4):245-259.

82. Consoli A, Formoso G. Potential side effects to GLP-1 agonists: understanding their safety and tolerability. Expert Opin Drug Saf. 2015; 14(2):207-218.

83. Bjerre Knudsen L, Madsen LW, Andersen S, et al. Glucagon-like peptide-1 receptor agonists activate rodent thyroid $\mathrm{C}$-cells causing calcitonin release and C-cell proliferation. Endocrinology. 2010;151(4):1473-1486.

84. Waser B, Beetschen K, Pellegata NS, Reubi JC. Incretin receptors in non-neoplastic and neoplastic thyroid $\mathrm{C}$ cells in rodents and humans: relevance for incretin-based diabetes therapy. Neuroendocrinology. 2011;94(4):291-301.

85. van Can J, Sloth B, Jensen CB, Flint A, Blaak EE, Saris WH. Effects of the once-daily GLP-1 analog liraglutide on gastric emptying, glycemic parameters, appetite and energy metabolism in obese, non-diabetic adults. Int J Obes (Lond). 2014;38(6):784-793.

86. Horowitz M, Flint A, Jones KL, et al. Effect of the once-daily human GLP-1 analogue liraglutide on appetite, energy intake, energy expenditure and gastric emptying in type 2 diabetes. Diabetes Res Clin Pract. 2012;97(2):258-266.

87. Williams DL, Baskin DG, Schwartz MW. Leptin regulation of the anorexic response to glucagon-like peptide-1 receptor stimulation. Diabetes. 2006;55(12):3387-3393.

88. Clemmensen C, Chabenne J, Finan B, et al. GLP-1/glucagon coagonism restores leptin responsiveness in obese mice chronically maintained on an obesogenic diet. Diabetes. 2014;63(4):1422-1427.

89. Müller TD, Sullivan LM, Habegger K, et al. Restoration of leptin responsiveness in diet-induced obese mice using an optimized leptin analog in combination with exendin-4 or FGF21. J Pept Sci. 2012;18(6) 383-393.

90. Iepsen EW, Lundgren J, Dirksen C, et al. Treatment with a GLP-1 receptor agonist diminishes the decrease in free plasma leptin during maintenance of weight loss. Int J Obes (Lond). In press 2014.

91. Cotugno M, Nosso G, Saldalamacchia G, et al. Clinical efficacy of bariatric surgery versus liraglutide in patients with type 2 diabetes and severe obesity: a 12-month retrospective evaluation. Acta Diabetol. In press 2014.

\section{Publish your work in this journal}

Drug Design, Development and Therapy is an international, peerreviewed open-access journal that spans the spectrum of drug design and development through to clinical applications. Clinical outcomes, patient safety, and programs for the development and effective, safe, and sustained use of medicines are a feature of the journal, which

\section{Dovepress}

has also been accepted for indexing on PubMed Central. The manuscript management system is completely online and includes a very quick and fair peer-review system, which is all easy to use. Visit http://www.dovepress.com/testimonials.php to read real quotes from published authors. 